\title{
Distribution of Cytokeratin 17 in the Parenchymal Elements of Rat's Submandibular Glands Subjected to Fractionated Radiotherapy
}

\author{
Sherif S. Hassan ${ }^{1}$ \\ Mahmoud A. Attia² \\ Alaa M. Attia ${ }^{3}$ \\ ${ }^{1}$ Department of Oral Biology and Dental Anatomy, Faculty of \\ Dentistry, Al-Azhar University (Assiut), Egypt and, Umm Al-Qura \\ University, Saudi Arabia \\ 2 Department of Oral Pathology, Faculty of Dentistry, Al-Azhar \\ University, (Assiut), Egypt and Faculty of Applied Medical Science, \\ Al-Baha University, Saudi Arabia \\ 3 Department of Oral Medicine and Periodontology, Faculty of \\ Dentistry, Al-Azhar University (Assiut), Egypt and Umm Al-Qura \\ University, Saudi Arabia \\ ${ }^{4}$ Department of Oral and Maxillofacial Surgery Faculty of Dentistry, \\ Al-Azhar University (Assiut), Egypt \\ ${ }^{5}$ Department of Pedodontics and Oral Health, Faculty of Dentistry, \\ Al-Azhar University (Cairo), Egypt and Umm Al-Qura University, \\ Saudi Arabia
}

Reda A. Nofal ${ }^{4}$ Adel Fathi ${ }^{5}$

Address for correspondence Alaa Moustafa Attia, PhD, Department of Basic and Oral Sciences (Periodontics Division), Faculty of Dentistry, Umm Al-Qura University, P.O. Box 715, Makkah 24238, Saudi Arabia (e-mail: alaamattiam@gmail.com).

Eur J Dent:2020;14:440-447

\begin{abstract}
Keywords

- fractionated

- radiotherapy

- submandibular

- Cytokeratin 17

Objectives The aim of this research was to study the intensity of cytokeratin 17 (CK17) in the parenchymal elements of rat's submandibular salivary glands subjected to fractionated radiotherapy regimen that used for treatment of head and neck malignancy.

Materials and Methods Twenty male albino rats were divided into two equal groups (normal and irradiated). The irradiated group received a radiation dose of 5 Grays daily for 5 days using therapeutic X-ray beam. Six months later, submandibular gland was dissected out and prepared for both histological and immunohistochemical studies.

Results Submandibular gland of irradiated group showed two different types of histological alterations. The first alteration showed severe gland atrophy replaced by either fibrous or fatty tissues. In some sections, the gland exhibited proliferating activity in the form of profuse amounts of mitotic figures. Immunohistochemical examination of control glands displayed a mild cytoplasmic expression of CK17 of duct cells as well as serous acini. The staining pattern was either diffused or concentrated at the basal part of the cell with negative expression at its apical part.

Statistical Analysis Expression of CK17 in submandibular gland of irradiated group displayed a highly significant differences $(P<0.001)$ in both intercalated and striated ducts. Many serous acini displayed a highly significant differences $(P<0.001)$ whereas, mucous acini were negatively stained.

Conclusions The intensity and diffusion of CK17 expression in our results foretell the pathological effect of radiotherapy on the intermediate filaments of salivary gland parenchyma that interfered with production and/or secretion of saliva leading to xerostomia.
\end{abstract}




\section{Introduction}

Submandibular glands are major exocrine glands secrete saliva into the oral cavity. Salivary glands play an important role in the oral health by the production of saliva secreted mainly from submandibular glands $65 \%$, parotid glands $23 \%$, sublingual glands $4 \%$, and the remaining $8 \%$ being provided by the minor numerous glands. ${ }^{1}$ Saliva performs a lot of functions within the oral cavity as it moistens mucous membrane, facilitates speech, contains antimicrobial enzymes and maintains the tooth integrity. ${ }^{2,3}$

Histologically, submandibular glands consist of parenchymal elements (acini, ducts, and myoepithelial cells) and richly vascularized connective tissue stroma carrying nonmyelinated nerve fibers. ${ }^{4}$ Acini are a tubular shaped structure responsible for production of primary saliva. Each one of the acini is consists of a group of pyramidal secretory cells attached to each other by junctional complexes and enclosed central lumen. Duct system of male rat consists of short narrow intercalated ducts connecting the acini to the granular convoluted tubule, which in turn drains primary saliva into the striated ducts ranging from columnar cells to stratified squamous ones. Also, the intralobular ducts drain the modulated saliva into a system of excretory ducts that open into the oral cavity. Stem cell is another cell type in the salivary glands found at both excretory and striated ducts. ${ }^{5}$ The stem cells generate progenitor cells that replace the acinar and ductal cells. ${ }^{4}$ The life span of acinar and ductal cells in rats is reported to be 60 to 120 days. ${ }^{6}$

Radiotherapy represents one of the classical options for managing oral and paraoral malignant diseases. ${ }^{7}$ Fractionated radiotherapy was the commonly used treatment plane of malignant carcinoma of the neck, in which major salivary glands are included within the radiation treatment site. ${ }^{8}$ Loss of saliva production is the main problem of radiation therapy due to damage of salivary gland tissues and loss of secretory ability leading to xerostomia accompanied by dysphagia with loss of taste sensation, difficulty speaking, with increased rates of dental caries which impact the quality of life as reported by many authors. ${ }^{9-14}$ The cause of xerostomia from radiation therapy is mainly due to the damaging effects of both parotid and submandibular glands which secrete more than $80 \%$ of daily saliva. ${ }^{15}$ In addition, many authors noted that xerostomia resulted during radiotherapy of head and neck cancer can already be observed after few fractions and may persist during the rest of the patient's life. ${ }^{16,17}$ Many advances to manage xerostomia caused by radiotherapy still only give a partial solution. Jensen et al noted that stem cells implant to submandibular glands are promising approaches for the regeneration of radiated gland tissue. ${ }^{18}$

The presence of salivary glands in the treatment site leads to disturbances of both physiological function and histological structure. ${ }^{19}$ Significant histological alterations including cell necrosis, nuclear fragmentation, cell membrane injury, and vacuolation were recorded in the irradiated animal. ${ }^{5}$ Atrophy of irradiated salivary gland parenchymal tissue was the end result which replaced by either fibrous or fatty tissue. ${ }^{20}$ The irradiated salivary glands showed highly significant reduction in acinar size with increase in inter-acinar space. Serous acini are more susceptible to morphological changes while both mucous acini and ductal cells did not show apparent differences. ${ }^{5,21}$

Reduction of saliva flow rates and changes in its contents which are associated with loss of parenchymal cells was the end sequala of radiation injuries of salivary glands..$^{22} \mathrm{~A}$ prominent decrease in saliva was seen 7 days after radiotherapy regimen to treat cancers and many cases showed recovery 2 months after complete treatment. ${ }^{4}$ Loss and recovery of saliva production is dose dependent, as reported by Funegard, who noted that irradiation with total doses more of than $65 \mathrm{~Gy}$ led to permanent loss of salivary function and recovery could be seen with total dose less than $52 \mathrm{~Gy} .{ }^{4}$

Immunohistochemistry is a technique for identifying intracellular constituents (antigen) by means of antigenantibody interaction. An antigen (immunogen) bears one or more antibody binding sites, which are highly specific regions termed epitopes. ${ }^{23}$ Immunoglobulin $G$ is the common antibody used for immunohistochemistry produced by immunizing an animal with purified specific antigen (immunogen). The animal was mounting humeral immune response to this specific immunogen and produced antibody specific to the epitope termed monoclonal antibody which can be isolated from the animal to be used in the intracellular expression of this antigen. ${ }^{24}$

Cytokeratin intermediate filaments are a family of proteins coded by different genes and distributed in various epithelial cells. ${ }^{23}$ The proposed functions of cytokeratin were to maintain the cellular architecture, anchor cells together, facilitate transport of materials within the cells, and play a major role in maintaining tensile strength and integrity of epithelial tissues. Immunohistochemically, cytokeratin are important markers as they are stable, resist degradation, formalin fixed, and paraffin embedded. Also, cytokeratin intermediate filaments show great fidelity of expression and are very antigenic. ${ }^{25}$ At present, 30 types of cytokeratin have been identified. ${ }^{23}$ Normally, salivary gland expressed Cytokeratin 17 (CK17) which are related to the cytoplasm of all duct cells. ${ }^{26}$ On the other hand, acinar cells expressed CK17 but to lesser extent. ${ }^{27}$

Many authors studied the expression of cytokeratin in irradiated submandibular gland of rats with a dose of 20 to $60 \mathrm{~Gy}$ at time points 4 and 6 months. Monoclonal antibody against CK17 was expressed in all duct cells from moderate to strong intensity. In most cases of $20 \mathrm{~Gy}$ group, cytokeratin staining profile was not differing significantly from the control one. Differences in immunoreactivity were seen between irradiated gland and nonirradiated one at a dose of 40 to $60 \mathrm{~Gy}$, the stronger expression was dose dependent. ${ }^{28,29}$

The purpose of our study was to examine the histopathological and immunohistochemical effects of treatment with five successive radiotherapeutic doses of $5 \mathrm{~Gy}$ to the neck region on the intracellular structure of submandibular gland of rats.

\section{Materials and Methods}

\section{Grouping}

Twenty mature male albino rats (weight $160-180$ g) were obtained from Laboratory Animal house, Faculty of Veterinary 
Medicine, Cairo University, Egypt. Rats were kept in polycarbonate cages (four rats per cage) under 8 to 16 dark/light cycle. Mixture of hard and soft food was given ad-libitum with unrestricted access to water. Rats were maintained in animal care facility for 1 week before being used in the experiment. Animals were divided into two equal groups (control group I and irradiated group II).

\section{Anesthesia and Radiation}

The experimental group received a dose of fractionated radiation of $5 \mathrm{~Gy} / \mathrm{d}$ for five successive days with a total dose of $25 \mathrm{~Gy}$. At every day of radiation exposure, all rats were restrained carefully and anesthetized by intraperitoneal injection of pentobarbital sodium ( $30 \mathrm{mg} / \mathrm{kg}$ body weight). Rats of radiated group were shielded by $5-\mathrm{mm}$ thickness of lead slide for protection of vital organs leaving only the neck

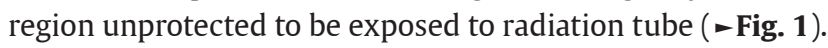
Rats received radiation dose of $5 \mathrm{~Gy}$ using therapeutic X-ray beam (Philips SL 75.5) operated at $235 \mathrm{kV}, 15$ Milli-Amber, and maximum field size $40 \times 40 \mathrm{~mm}$ at $43 \mathrm{~cm}$ from the focus. Exposure time obtained was $0.85 \mathrm{~Gy} / \mathrm{min}$ for approximately 6 minutes. Radiation was administered between 8:00 am and $12.00 \mathrm{pm}$. Control rats were anesthetized without radiation exposure.

\section{Histopathological Examinations}

Six months post irradiation, rats of both groups were anesthetized, salivary glands were carefully dissected and fixed in neutral buffered $10 \%$ formalin. Tissue staining was performed using paraffin-embedded tissue sections of 5- $\mu \mathrm{m}$ thickness. Effects were judged by hematoxylin and eosin (H\&E) stained sections for histopathological examinations.

\section{Immunohistochemical Examinations}

Immunohistochemical staining was done using specific antibodies for the expression of CK17. The sections were mounted on silicone-coated glass slide, deparaffinized in xylene, and rehydrated with a descending series of ethanol. After blocking endogenous peroxidase activity with methanol containing $0.3 \% \mathrm{H}_{2} \mathrm{O}_{2}$ for 30 minutes, antigenicity was retrieved by microwave heating for a period of 5 minutes (two to three times) in a citrate buffer (pH: 6). Then, blocking

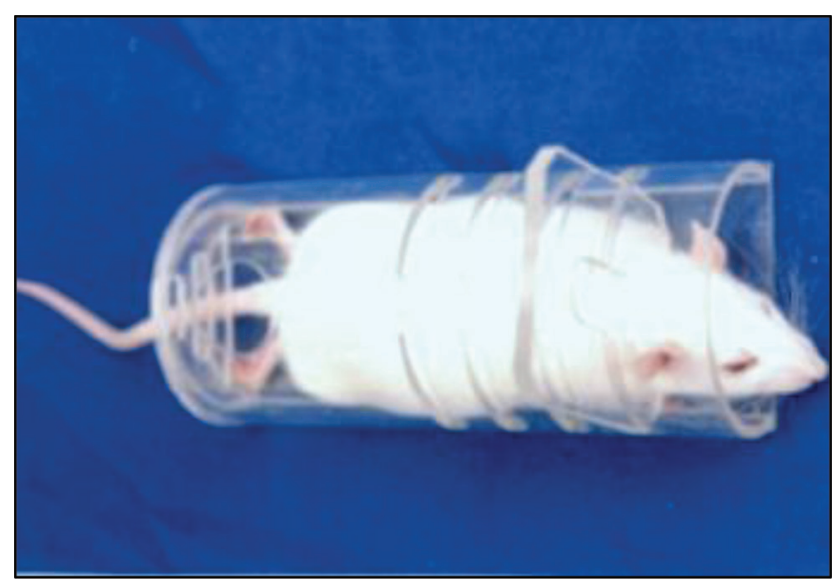

Fig. 1 Rat handling restrainer during anesthesia. reagent was applied for 10 minutes to reduce nonspecific staining. CK17 was identified by monoclonal anti-CK17 E3 antibody (Sigma) using labeled streptavidin biotin method and hematoxylin counterstain. The positive staining reaction appeared in the form of brownish staining which reflected the intracellular distribution of CK17 within the gland parenchyma tissue cells. The intensity of staining was assessed semi quantitively and scored as follows: negative staining $(0)$, trace or weak $(>0)$, mild $(>1)$, moderate $(>2)$, and strong staining (>3). For cytokeratin evaluation method, first, samples of both groups were numbered to hide whether it was from a control or exposed to radiation to exclude the prediction of the results of the microscopic examination. All samples were examined microscopically by two different viewers of the working group separately. Each member recorded the cytokeratin staining intensity of each sample twice over the course of 2 days; each time four readings of different places of the same sample and the average of the resulting measurements were taken as shown in - Tables $\mathbf{1}$ and $\mathbf{2}$.

Photos were taken by the means of Olympus BH2 microscope equipped with an Olympus DP50 digital camera (Olympus Optical Company Ltd.; Melville, New York, United States) and a Nikon Eclipse 80i microscope and Evolution MP 5.1 Mega-pixel FireWire Digital CCD Color Camera Kit (Media Cybernetics, Inc.; Rochester, New York, United States).

\section{Statistical Analysis}

Data were written and calculate to be analyzed through the Statistical Package for Social Science (SPSS), version 23 (IBM Inc., United States). Descriptive data of both groups were presented as mean, standard deviation (SD), and by using the Levene's test to assess the equality of variances for the variable calculated data. The comparison between two independent groups with quantitative data and parametric distribution was done by using an independent $t$-test. $p$-Value was considered significant at level $\leq 0.05$.

\section{Results}

\section{Histopathological Findings}

Histological findings of submandibular gland of control group revealed a lobular parenchymal tissue filled with closely packed predominating serous acini and mucous acini of lesser degree. Both serous and mucous acini are composed of pyramidal-shaped cells, surrounded by basement membrane and separated from each other by connective tissue stroma. Many mucous acini are capped by some serous cells referred to as serous demilune. Duct branches of control group are composed of intercalated, striated, and CGT as well as excretory ducts. Intercalated duct is composed of cuboidal cells encircling small lumen and closely located with the acini. Striated duct is composed of columnar cells while excretory duct system varies from columnar, pseudostratified columnar into stratified squamous epithelium at the connection with the oral cavity. All parenchymal elements were supported with connective tissue stroma dividing the gland into lobes and lobules (-Fig. 2). 
Table 1 Cytokeratin intensity upon animals in acinar cells of both groups, negative staining (0), trace or weak $(>0)$, mild $(>1)$, moderate $(>2)$, and strong staining $(>3)$

\begin{tabular}{|c|c|c|c|c|c|c|c|c|c|c|}
\hline \multirow[t]{4}{*}{ Rats } & \multicolumn{10}{|c|}{ Intensity of CK17 expression in acinar cells } \\
\hline & \multicolumn{5}{|c|}{ Control group } & \multicolumn{5}{|c|}{ Irradiated group } \\
\hline & \multicolumn{4}{|c|}{ Field number } & & \multicolumn{4}{|c|}{ Field number } & \multirow[b]{2}{*}{ Average } \\
\hline & 1 & 2 & 3 & 4 & Average & 1 & 2 & 3 & 4 & \\
\hline 1 & 0 & 1 & 0 & 1 & 0.50 & 0 & 1 & 0 & 2 & 0.75 \\
\hline 2 & 1 & 0 & 0 & 2 & 0.75 & 2 & 1 & 2 & 1 & 1.50 \\
\hline 3 & 0 & 1 & 2 & 1 & 1.00 & 1 & 2 & 1 & 0 & 1.00 \\
\hline 4 & 1 & 0 & 1 & 0 & 0.5 & 2 & 1 & 0 & 1 & 1.00 \\
\hline 5 & 0 & 0 & 1 & 2 & 0.75 & 0 & 1 & 2 & 2 & 1.25 \\
\hline 6 & 0 & 2 & 1 & 1 & 1.00 & 0 & 2 & 1 & 2 & 1.25 \\
\hline 7 & 0 & 0 & 1 & 0 & 0.25 & 1 & 2 & 0 & 1 & 1.00 \\
\hline 8 & 1 & 0 & 0 & 0 & 0.25 & 2 & 1 & 1 & 0 & 1.00 \\
\hline 9 & 0 & 1 & 1 & 1 & 0.75 & 1 & 2 & 1 & 1 & 1.25 \\
\hline \multirow[t]{2}{*}{10} & 0 & 0 & 2 & 0 & 0.50 & 1 & 2 & 0 & 0 & 0.75 \\
\hline & \multicolumn{4}{|c|}{ Mean \pm SD } & 0.625 & \multicolumn{4}{|c|}{ Mean \pm SD } & 1.075 \\
\hline
\end{tabular}

Abbreviation: SD, standard deviation.

Table 2 Cytokeratin intensity upon animals in duct cells of both groups, negative staining (0), trace or weak $(>0)$, mild $(>1)$, moderate $(>2)$, and strong staining $(>3)$

\begin{tabular}{|c|c|c|c|c|c|c|c|c|c|c|}
\hline \multirow[t]{4}{*}{ Rats } & \multicolumn{10}{|c|}{ Intensity of CK17 expression in duct cells } \\
\hline & \multicolumn{5}{|c|}{ Control group } & \multicolumn{5}{|c|}{ Irradiated group } \\
\hline & \multicolumn{4}{|c|}{ Field number } & & \multicolumn{4}{|c|}{ Field number } & \multirow[b]{2}{*}{ Average } \\
\hline & 1 & 2 & 3 & 4 & Average & 1 & 2 & 3 & 4 & \\
\hline 1 & 2 & 2 & 1 & 1 & 1.50 & 2 & 2 & 3 & 2 & 2.25 \\
\hline 2 & 2 & 1 & 1 & 2 & 1.50 & 2 & 1 & 4 & 1 & 2.00 \\
\hline 3 & 0 & 2 & 2 & 1 & 1.25 & 2 & 3 & 2 & 3 & 2.50 \\
\hline 4 & 1 & 2 & 2 & 0 & 1.25 & 3 & 1 & 2 & 1 & 1.75 \\
\hline 5 & 2 & 1 & 1 & 0 & 1.00 & 3 & 2 & 3 & 2 & 2.50 \\
\hline 6 & 0 & 1 & 2 & 2 & 1.25 & 2 & 1 & 3 & 2 & 2.00 \\
\hline 7 & 1 & 2 & 1 & 2 & 1.50 & 2 & 3 & 3 & 2 & 2.50 \\
\hline 8 & 2 & 1 & 1 & 1 & 1.25 & 2 & 1 & 2 & 1 & 1.50 \\
\hline 9 & 3 & 1 & 0 & 1 & 1.25 & 3 & 1 & 0 & 1 & 1.25 \\
\hline \multirow[t]{2}{*}{10} & 2 & 1 & 2 & 3 & 2.00 & 3 & 1 & 2 & 3 & 2.25 \\
\hline & \multicolumn{4}{|c|}{ Mean \pm SD } & 1.375 & \multicolumn{4}{|c|}{ Mean \pm SD } & 2.050 \\
\hline
\end{tabular}

Abbreviation: SD, standard deviation.

Histological findings of submandibular gland of fractionated radiation group showed severe gland atrophy varying from decrease of the acinar size to complete loss of gland architecture. The atrophied acini are replaced with either fibrous or adipose tissues (-Fig. 3). Acinar cell nuclei of irradiated gland vary greatly in shape and size (poikilocytosis) with increased chromatin condensation (pyknosis) and many sections exhibited certain amount of mitotic figures some of them of abnormal values. The remaining viable acini appeared smaller, further apart, and interspersed within the fibrosis. Both intercalated and striated ducts were dilated with wide lumen, lined up by flat cells instead of normal cuboidal appearance.

\section{Immunohistochemical Findings}

Examination of control submandibular gland sections incubated with anti-cytokeratin E3 antibody against CK17 displayed a weak to mild expression in all intercalated, striated, and excretory duct cells as well as serous acinar cells with negative staining mucous acini (-Fig. 4). The staining pattern was either diffuse and uniform or concentrated lateral and basal to the nucleus with weak expression at the apical part of cell cytoplasm. In many sections, the main excretory duct that lined by stratified squamus epithelium exhibited moderate expression at the basal cell layer with weak expression at rest of the superficial layers. The cells of granular convoluted tubules expressed a weak to mild staining reaction in 


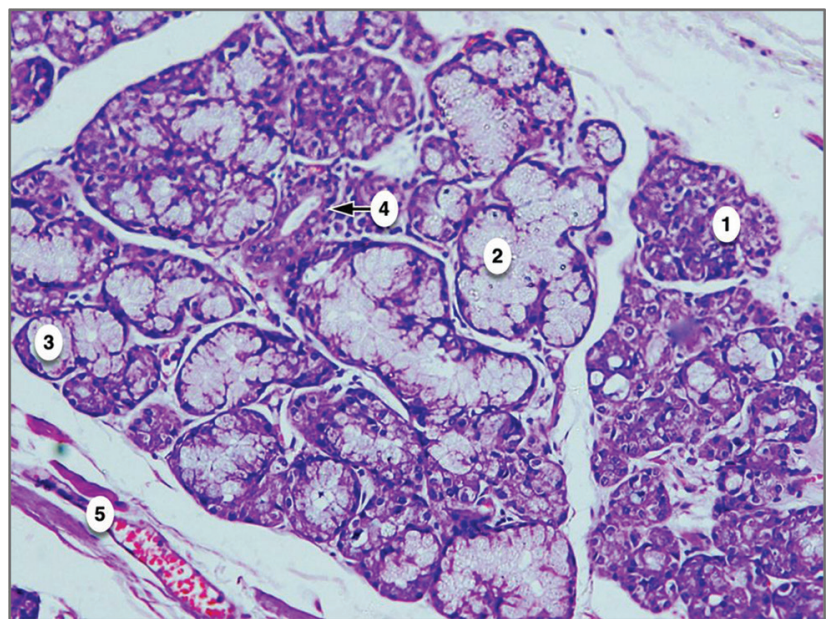

Fig. 2 Control submandibular gland shows serous acini(1), mucous acini(2), serous demilune ${ }^{(3)}$, striated $\operatorname{duct}^{(4)}$, blood vessel ${ }^{(5)}$, $(H \& E, \times 100) . H \& E$, hematoxylin and eosin.

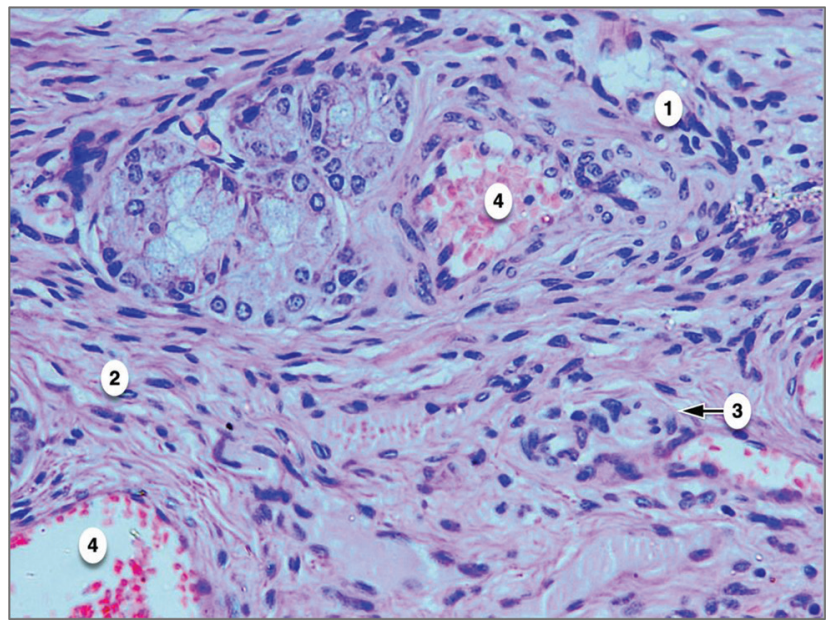

Fig. 3 Irradiated submandibular gland shows loss of gland architecture $^{(1)}$, fibrosis ${ }^{(2)}$, acinar atrophy ${ }^{(3)}$, extravasated blood ${ }^{(4)}$, (H\&E, $\left.\times 200\right)$. $\mathrm{H} \& \mathrm{E}$, hematoxylin and eosin.

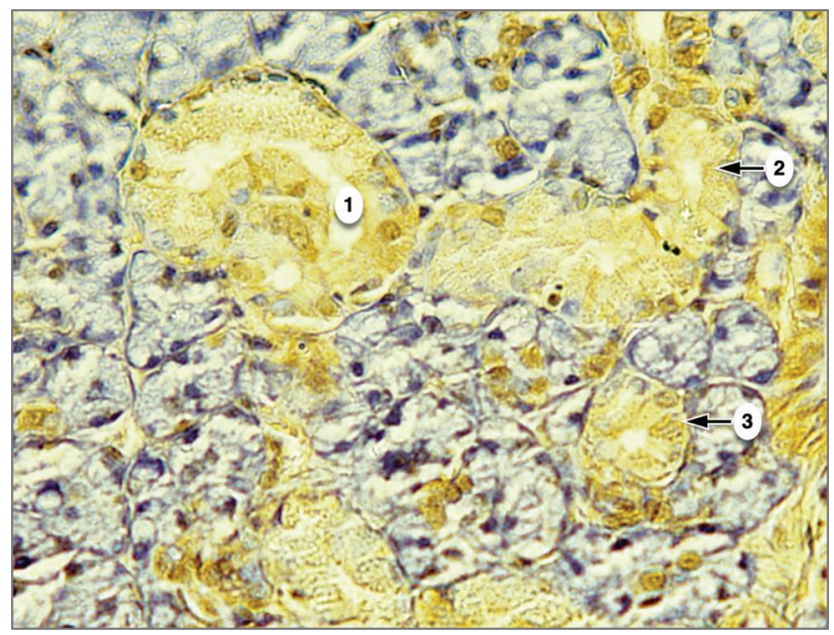

Fig. 4 Expression of CK17 in control submandibular gland: mild in all striated duct ${ }^{(1)}$, intercalated $\operatorname{duct}^{(2)}$, and serous acini(3) $(\times 400)$. CK17, Cytokeratin 17. a diffused pattern. Additionally, the intensity of CK17 in the duct cell displayed a significant $(p<0.001)$ expression in both intercalated and striated ducts compared with that found in serous acini.

Expression of CK17 in submandibular gland of fractionally irradiated group displayed highly significant values $(p<0.001)$ moderate to strong cytoplasmic expression in both intercalated and striated ducts (-Figs. 6 and 7; - Tables 1 to 4 ). The staining pattern of the duct cells was either strong at the apical part of cytoplasm with mild staining at basal part or diffused throughout the cell cytoplasm. Some excretory ducts displayed strong expression either concentrated at their apical cell part with mild to moderate expression at their basal part or diffuse throughout the duct cells. Many serous acini displayed highly significant differences $(p<0.001)$ in mild to moderate expression of CK17 of diffuse type while mucous acini were negatively stained. Some degenerated acini and ducts showed mild cytokeratin expression (- Tables 1 to 4 ).

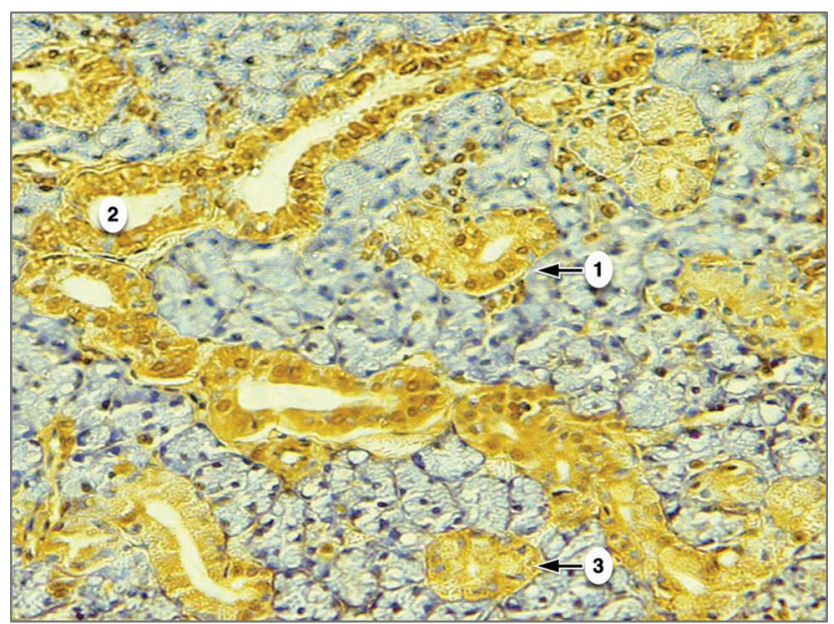

Fig. 5 Expression of CK17 in radiated submandibular gland: moderate in intercalated ducts(1), striated ducts ${ }^{(2)}$, and serous acini ${ }^{(3)}$, (×200). CK17, Cytokeratin 17.

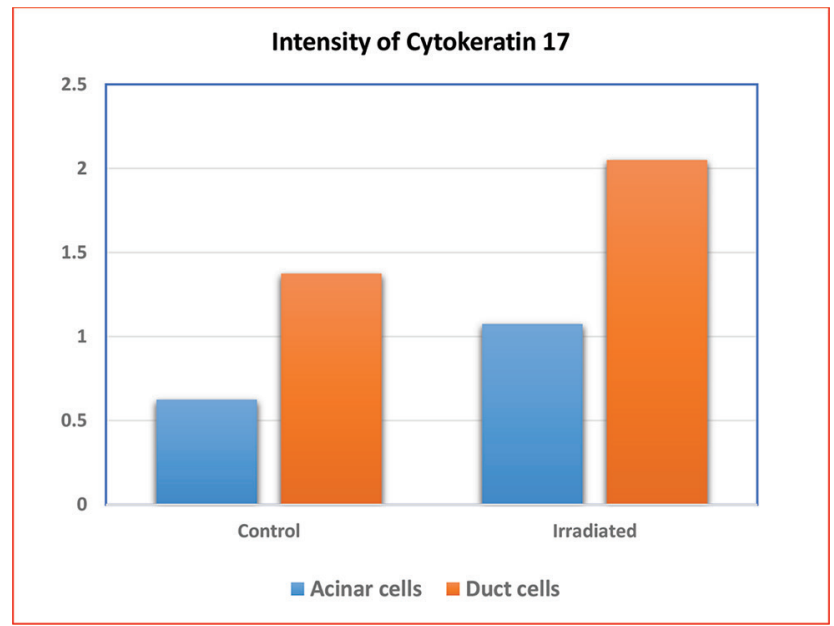

Fig. 6 Expression of CK17 upon control acinar and duct cells shows intensive expression in duct cell than that of acinar one. CK17, Cytokeratin 17. 


\section{Discussion}

In general, damage to the salivary glands is a well-known sequela of radiation therapy of head and neck malignancies in both human and experimental animals. Both clinical and experimental data on the radiation-induced pathomechanisms involved in the process of fibrosis, atrophy, and xerostomia are still doubtful. Our research focused on studying the tissue changes that were seen 6 months after the last radiation doses, to exclude any possibility of regeneration. The results showed the persistent of the gland destruction in the form of atrophy with loss of architecture and replacement by fibrosis which give an impression of permanence. Persistence of pathological changes in our results is inconsistent with the results of many authors who said that the process of healing of the gland parenchyma was performed 2 months post radiation. ${ }^{5,8}$ Emmerson et al reported that

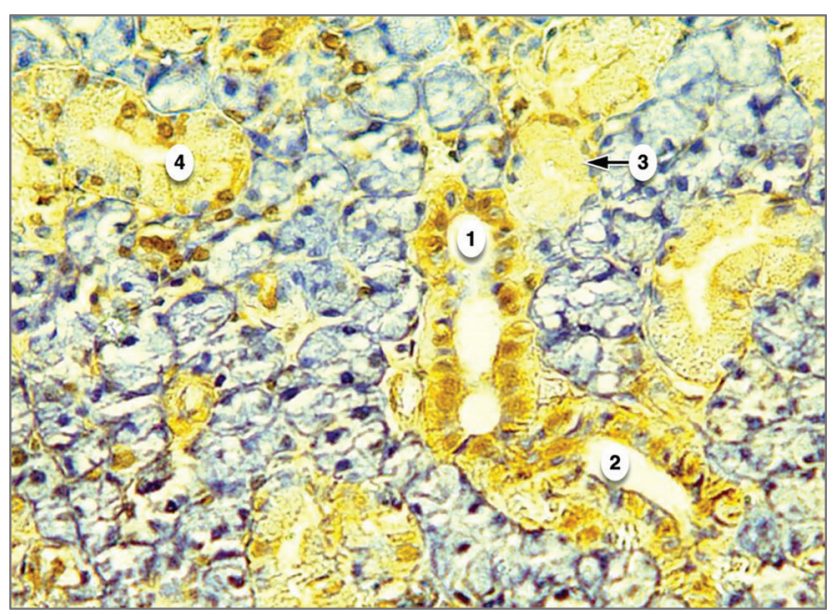

Fig. 7 Expression of CK17 in radiated submandibular gland: moderate in striated $\operatorname{duct}^{(1)}$, and intercalated ducts ${ }^{(2)}$, mild in serous acini ${ }^{(3)}$, and $\mathrm{GCT}^{(4)},(\times 200)$. CK17, Cytokeratin 17; GCT, granular convoluted tubules. differentiaition of progenitor cell population is responsible for the extensive regenerative capacity of salivary glands. ${ }^{30}$

The observed alteration appears to have been the result of the harmful effect of radiation on DNA replication of parenchymal cells leading to cell death. This result conforms with the explanation of many investigators. ${ }^{17,31,32}$ Additionally, many authors noted that, the pathogenesis of irradiation-induced damage of the salivary gland cells is due to high radiosensitivity of both duct and acinar cells in spite of their low rate of mitosis. ${ }^{32,33}$ The histopathological observation seen in many sections that characterized by vacuolated cytoplasm and large atypical nuclei with high proliferating activity giving an indication toward the development of pathological tissue rather than the process of regeneration. Krishnan et al noted that cytoplasmic vacuolation is related to the effect of irradiation on the cell membrane causing cell irregularities with reduced secretion of amylase. ${ }^{5}$ The intercalated ducts in the present investigation became more numerous due to acinar atrophy which indicated the earlier destruction of the acinar cells prior to the duct cells. This finding was supported by Fajardo and Berthrong, which noted that serous acini was the most sensitive part of the salivary gland followed by the mucous acini and duct cell. ${ }^{34}$

Cytokeratin is a member of the intermediate filament family found in the epithelial cells and plays an important role in the structuring of both cells and tissues. Expression of cytokeratin has been closely linked to differentiation state of epithelial cells. ${ }^{35}$ Our results revealed two different staining patterns of cytokeratin in the acinar cells of control group, one diffuse and other concentrated at the basal cell part with negative staining at the luminal part. The variability of cytokeratin distribution thought to be related to the functional activity of the acinar cells in which the diffuse pattern referred to the resting state of the gland while the negative expression of cytokeratin at the luminal part related to the secretory state with active ionic exchange which agree with many authors..$^{28,29}$ The pattern of expression of

Table 3 Descriptive statistics of control and irradiated acinar and duct cells

\begin{tabular}{|l|c|c|c|c|c|c|}
\hline & Range & Minimum & Maximum & Mean & SE & SD \\
\hline Acinar cells (control) & 0.75 & 0.25 & 1.00 & 0.6250 & 0.08539 & 0.27003 \\
\hline Acinar cells (irradiated) & 0.75 & 0.75 & 1.50 & 1.0750 & 0.07500 & 0.23717 \\
\hline Duct cells (control) & 1.00 & 1.00 & 2.00 & 1.3750 & 0.08539 & 0.27003 \\
\hline Duct cells (irradiated) & 1.25 & 1.25 & 2.50 & 2.0500 & 0.13844 & 0.43780 \\
\hline
\end{tabular}

Abbreviations: SD, standard deviation; SE, standard error.

Table 4 Revealed the independent comparisons of $t$-test between acinar and duct cells

\begin{tabular}{|c|c|c|c|c|}
\hline & Mean & SD & $T$-value & $p$-Value \\
\hline Acinar cells (control) & 0.6250 & 0.27003 & \multirow[t]{2}{*}{3.959} & \multirow[t]{2}{*}{$<0.001$} \\
\hline Acinar cells (irradiated) & 1.0750 & 0.23717 & & \\
\hline Duct cells (control) & 1.3750 & 0.27003 & \multirow[t]{2}{*}{4.150} & \multirow[t]{2}{*}{$<0.001$} \\
\hline Duct cells (irradiated) & 2.0500 & 0.43780 & & \\
\hline
\end{tabular}

Abbreviation: SD, standard deviation 
CK17 concentrated at the basal cell part might be related to an increase in the tensile strength of the basal part of the acinar cells facing myoepithelium leading to the increase in the squeezing ability, thus pushing saliva via the lumen to the duct system. On the other hand, expression of CK17 in the duct cells appeared more intensive than in the acinar cells which might be related to the differentiation stage of the parenchymal elements, in which, the acini are higher differentiated cells allover the gland.

Irradiated group of the present study revealed a distinct immunostaining of CK17 in both acinar and ductal cells, some of which are of diffuse type. However, many irradiated sections showed strong expression of CK17 concentrated at the luminal part of the cell cytoplasm and decreased at their basal part. The luminal arrangement of cytokeratin might interfere with the functions of the parenchymal cells leading to hypo-salivation, these results were in agreement with many investigators. ${ }^{29,35,36}$ The distribution patterns of cytokeratin at the luminal cell part of the duct cells might interfere with the saliva modification of the duct cells. Also, the diffuse pattern of cytokeratin expression indicates damaging effects all over the cells. It is thought that the luminal distribution pattern represents an early stage of radiation damage, whereas the diffuse pattern was the advanced one. The study concludes that the intensity and diffusion of CK17 expression in our results foretell the pathological effect of radiotherapy on the intermediate filaments of salivary gland parenchyma that interfered with the production and/or secretion of saliva leading to xerostomia.

\section{Conflict of Interest}

None declared.

\section{Acknowledgment}

The authors extend more sincere thanks and greetings to the beloved son Kareem Sherif, who gave us the inspiration and support to complete this research.

\section{References}

1 Dodds MW, Johnson DA, Yeh CK. Health benefits of saliva: a review. J Dent 2005;33(3):223-233

2 Schipper RG, Silletti E, Vingerhoeds MH. Saliva as research material: biochemical, physicochemical and practical aspects. Arch Oral Biol 2007;52(12):1114-1135

3 Sreebny L, Vissink A, Dry Mouth, the Malevolent Symptom: A Clinical Guide. Singapore: Wiley-Blackwell; 2010 212-223

4 Funegard U, Fractionated Irradiation of Salivary Glands, Loss and Protection of Function. Tryckeri: Umea University; 1995 6-85

5 Krishnan M, Tennavan A, Saraswathy S, Sekhri T, Singh AK, Nair V. Acute radiation-induced changes in Sprague-Dawley rat submandibular glands: a histomorphometric analysis. World J Oncol 2017;8(2):45-52

6 Zajicek G, Schwartz-Arad D, Arber N, Michaeli Y. The streaming of the submandibular gland. II: parenchyma and stroma advance at the same velocity. Cell Tissue Kinet 1989;22(5):343-348
7 De Felice F, Tombolini M, Musella A, Marampon F, Tombolini $\mathrm{V}$, Musio D. Radiation therapy and serum salivary amylase in head and neck cancer. Oncotarget 2017;8(52):90496-90500

8 Marmary Y, Adar R, Gaska S, et al. Radiation-induced loss of salivary gland function is driven by cellular senescence and prevented by IL6 modulation. Cancer Res 2016;76(5):1170-1180

9 Weng PL, Aure MH, Maruyama T, Ovitt CE. Limited regeneration of adult salivary glands after severe injury involves cellular plasticity. Cell Rep 2018;24(6):1464-1470.e3

10 Jensen SB, Pedersen AM, Reibel J, Nauntofte B. Xerostomia and hypofunction of the salivary glands in cancer therapy. Support Care Cancer 2003;11(4):207-225

11 Pringle S, Van Os R, Coppes RP. Concise review: adult salivary gland stem cells and a potential therapy for xerostomia. Stem Cells 2013;31(4):613-619

12 Hancock PJ, Epstein JB, Sadler GR. Oral and dental management related to radiation therapy for head and neck cancer. J Can Dent Assoc 2003;69(9):585-590

13 Nguyen NP, Smith HJ, Sallah S. Evaluation and management of swallowing dysfunction following chemoradiation for head and neck cancer. Curr Opin Otolaryngol Head Neck Surg 2007;15(2):130-133

14 Grundmann O, Fillinger JL, Victory KR, Burd R, Limesand KH. Restoration of radiation therapy-induced salivary gland dysfunction in mice by post therapy IGF-1 administration. BMC Cancer 2010;10:417-426

15 Wu VWC, Leung KY. A review on the assessment of radiation induced salivary gland damage after radiotherapy. Front Oncol 2019;9:1090

16 Chambers MS, Garden AS, Kies MS, Martin JW. Radiationinduced xerostomia in patients with head and neck cancer: pathogenesis, impact on quality of life, and management. Head Neck 2004;26(9):796-807

17 Coppes RP, Roffel AF, Zeilstra LJ, Vissink A, Konings AW. Early radiation effects on muscarinic receptor-induced secretory responsiveness of the parotid gland in the freely moving rat. Radiat Res 2000;153(3):339-346

18 Jensen SB, Vissink A, Limesand KH, Reyland ME. Salivary gland hypofunction and xerostomia in head and neck radiation patients. J Natl Cancer Inst Monogr 2019;2019(53):lgz016

19 Fox PC, van der Ven PF, Sonies BC, Weiffenbach JM, Baum BJ. Xerostomia: evaluation of a symptom with increasing significance. J Am Dent Assoc 1985;110(4):519-525

20 El-Mofty SK, Kahn AJ. Early membrane injury in lethally irradiated salivary gland cells. Int J Radiat Biol Relat Stud Phys Chem Med 1981;39(1):55-62

21 Stephens LC, King GK, Peters LJ, Ang KK, Schultheiss TE, Jardine $\mathrm{JH}$. Acute and late radiation injury in rhesus monkey parotid glands. Evidence of interphase cell death. Am J Pathol 1986;124(3):469-478

22 RobarJL, Day A, Clancey J, et al. Spatial and dosimetric variability of organs at risk in head-and-neck intensity-modulated radiotherapy. Int J Radiat Oncol Biol Phys 2007;68(4):1121-1130

23 Saad S, Sohair S, Tumor Markers. 1st ed. London, New York, Tokyo, Madras: Chapman \& Hall, Poka Raton Florida; 1998 1-16

24 Bancroft J, Gamble M, Theory and Practice of Histological Techniques. 5th ed. London, NY: Churchill Livingstone; 2002 593-598

25 Franke WW, Schiller DL, Moll R, et al. Diversity of cytokeratins. Differentiation specific expression of cytokeratin polypeptides in epithelial cells and tissues. J Mol Biol 1981;153(4):933-959

26 Sozmen M, Brown PJ, Eveson JW. Cytokeratin immunostaining in normal dog major and minor salivary glands. Vet Res 1998;29(5):457-465 
27 Burns BF, Dardick I, Parks WR. Intermediate filament expression in normal parotid glands and pleomorphic adenomas. Virchows Arch A Pathol Anat Histopathol 1988;413(2):103-112

28 Bartel-Friedrich S, Friedrich R, Lautenschlager C, Moll R, Holzhausen $\mathrm{H}$. Dose-response relationships on the expression profile of cytokeratin and vimentin in rats following fractionated irradiation. Anticancer Res 2000;20:4917-4926

29 Bartel-Friedrich S, Friedrich RE, Moll R, Lautenschläger C. Immunohistochemical detection of cytokeratins in the irradiated rat mandibular gland. Anticancer Res 1999;19(4A): 2405-2409

30 Emmerson E, May AJ, Berthoin L, et al. Salivary glands regenerate after radiation injury through SOX2-mediated secretory cell replacement. EMBO Mol Med 2018;10(3):1-18

31 Hosseinimehr SJ. Trends in the development of radioprotective agents. Drug Discov Today 2007;12(19-20):794-805

32 Hiramatsu Y, Nagler RM, Fox PC, Baum BJ. Rat salivary gland blood flow and blood-to-tissue partition coefficients following X-irradiation. Arch Oral Biol 1994;39(1):77-80
33 Spraggs PD, Rose DS, Grant HR, Gallimore AP. Post-irradiation carcinosarcoma of the parotid gland. J Laryngol Otol 1994;108(5):443-445

34 Fajardo LF, Berthrong M. Radiation injury in surgical pathology. Part III. Salivary glands, pancreas and skin. Am J Surg Pathol 1981;5(3):279-296

35 Gustafsson H, Aalto Y, Franzén L, Thornell LE, Henriksson R. Effects of fractionated irradiation on the cytoskeleton and basal lamina in parotid glands-an immunohistochemical study. Acta Oncol 1998;37(1):33-40

36 Bonan PR, Kaminagakura E, Pires FR, Vargas PA, Almeida OP. Cytokeratin expression in initial oral mucositis of head and neck irradiated patients. Oral Surg Oral Med Oral Pathol Ora Radiol Endod 2006;101(2):205-211 